\title{
Fizik Tedavi ve Rehabilitasyon Merkezlerine Başvuran Yaşlıların Başvurma Nedenlerinin Araştırılması
}

\author{
Investigation of the Reasons for Applying to Physical Therapy and Rehabilitation \\ Centers by Elderly People
}

\section{Emre Özgür BULDUK* Sidıka BULDUK ${ }^{* *}$ Meltem SOYLU***}

\begin{abstract}
Özet: Bu araştırma Ankara'da fizik tedavi ve rehabilitasyon bölümlerine başvuran yaşlıların başvurma nedenleri amacıyla planlanmış ve yürütülmüştür. Çalışmaya, 65 yaş üstü 111 erkek, 101 kadın toplam 212 yaşlı alınmıştır. Araştırma sonucunda veriler SPSS programına aktarılmış $t$ testi ve ki kare testi kullanılarak değerlendirilmiştir. Araştırmada, erkeklerin \% 63.96'sının, kadınların \% 78.22'sinin aileleri ile evlerinde, erkeklerin \% 17.21'inin, kadınların ise \% 4.95'inin huzurevlerinde kaldıkları saptanmıştır. Cinsiyete göre BKİ değerleri istatistiksel olarak anlamlı bulunmuştur $(\mathrm{p}<0.05)$. Kadınların erkeklere göre daha sık sağlık kuruluşlarına başvurdukları tespit edilmiş̧ir. $(\mathrm{p}<0.01)$. Cinsiyete göre devamlı yürüyüşs ve kültür-fizik hareketi yapma durumları anlamlı $(\mathrm{p}<0.05)$, koşu yapmaları ise anlamsızdır $(\mathrm{p}>0.05)$. Yaşlıların fizik tedavi ve rehabilitasyon merkezlerine başvurma nedenleri; Kırık için, erkeklerin \% 41.44'ü, kadınların \% 48.51'i (p>0.05), romatizmal hastalıklar için erkeklerin \% 81.98'i ve kadınların \% 86.13'ü (p>0.05), nefes egzersizi için erkeklerin \% 37.03’ü, kadınların \% 18.81'i ( $\mathrm{p}<0.01$ ) başvurmuştur.
\end{abstract}

Anahtar sözcükler: Yaşlı, Rehabilitasyon, Fizyoterapi, Başvuru, Sağlık

Abstract: This study was conducted on 111 men and 101 women, a total of 212 seniors who were over the age of 65 and applied to physical therapy and rehabilitation departments of hospitals and private physical therapy and rehabilitation centers in Ankara in order to reveal the applying reasons to these departments and centers. The results of this research were evaluated using the $t$ test and the chi-square test in the SPSS program. In the study it was found that, $63.96 \%$ of men, $78.22 \%$ of women lived in their homes with their families. $17.21 \%$ of men, $4.95 \%$ of women were staying in nursing houses. BMI values by gender was statistically significant $(\mathrm{p}<0.05)$. In the study, women more often than men applied to health facilities $(p<0.01)$. The status of continuous walking and doing physical movements was significant $(p<0.05)$, while jogging was insignificant $(p>0.05)$ according to gender. Reasons for applying to physical therapy and rehabilitation centers were examined. For fracture treatment, $41.44 \%$ of men, $48.51 \%$ of women ( $>>0.05$ ), for rheumatic disease $81.98 \%$ of men and $86.13 \%$ of women ( $>0.05$ ), for breathing exercises $37.03 \%$ of men and $18.81 \%$ of women $(\mathrm{p}<0.01)$.

Keywords: Elder, Rehabilitation, Physiotherapy, Application, Health

\footnotetext{
* Yrd. Doç. Dr., Nuh Naci Yazgan Üniversitesi, Sağlık Bilimleri Fakültesi, Fizyoterapi ve Rehabilitasyon Bölümü, Kayseri, ozgurem@gmail.com

*** Prof. Dr., Gazi Üniversitesi, Mesleki Eğitim Fakültesi, Beslenme Bölümü, Ankara, bulduks@gmail.com

*** Yrd. Doç. Dr., Nuh Naci Yazgan Üniversitesi, Sağlık Bilimleri Fakültesi, Beslenme ve Diyetetik Bölümü, Kayseri, msoylu@nny.edu.tr
} 


\section{Giriş}

Yaşlanma hayatın bir devresi ve bir parçası olup tüm canlılarda görülen ve asla durmayan biyolojik bir süreçtir. Dünya Sağlık Örgütü (WHO)’ne göre 65 yaş ve üzeri bir kimse yaşlı olarak kabul edilmektedir (Nalbant, 2006; Ögüt, \& Atay, 2012). Yaşlanma terimi zamanın ilerlemesine bağlı olarak anatomik yapıda ve fizyolojik işlevlerde değişiklikler olarak tanımlanmaktadır. Sağlık; fiziksel, sosyal ve ruhsal yönden tam bir iyilik hali olarak kabul edilmektedir. Yaşlılığın durdurulması mümkün değildir. Yaşamın her evresinde sağlığın korunması en temel hedeftir. Yaşlı bireylerde belirli bir hastalık olmadığı halde fiziksel, sosyal ve psikolojik yönden bazı değişimler meydana gelmektedir. Bu değişikliklere uyum sağlama yaşlının yaşantısını etkilediği gibi bakımlarında da özel bir yaklaşımı gerektirmektedir (Durmuş, Cantürk, \& Topal, 2005; Beğer, \& Yavuzer, 2012).

Dünyada yaşlı nüfus oranı 1950'li yıllarda \% 8 iken 2009'da bu oran \% 11'e çıkmıştır. 2050 yılında yaşlı nüfus oranının \% 22'ye yükseleceği tahmin edilmektedir (United Nations, 2009). Gelişmiş ülkelerde görünür olan yaşlanma olgusu artık geri kalmış ve gelişmekte olan ülkelerinde önemle üzerinde durması gereken bir konu olmuştur. Gelişmiş ülkelerde 60 yaş üzeri popülasyon büyüme oranı \% 0.7 iken gelişmekte olan ülkelerde bu oran \% 2.2'dir. (World Health Organisation. 2011).

Dünyada demografik değişim benzer şekilde ülkemizde de yaşanmaktadır. Sağlık Bakanlığı İstatistik Yıllı̆̆g'’na göre Türkiye'de 65 yaş üzeri nüfus oranı 2000 yılında \% 5.2 iken 2010 yllında \% 7.2’ye yükselmiştir. Yaşlılık sadece bireyleri ilgilendiren bir sorun olmaktan çıkıp toplumsal bir sorun haline gelmektedir (Sağlık Bakanlığı, 2011).

Yaşlılarla ilgili fizik tedavi ve rehabilitasyon çalışmaları ülkemizde çeşitli üniversitelerde, devlet ve özel hastanelerde veya özel fizik tedavi ve rehabilitasyon merkezlerinde sürdürülmektedir. Çeşitli fizik tedavi ve rehabilitasyon uygulamaları ile yaşlı bireylerin yaşam doyumu ve yaşam kaliteleri arttırılmaya çalışılmaktadır (Morrison, 1969; Eser, et alii, 2008). Günümüzde yaşam süresinin uzaması ve değişen koşullar sonucunda yaşlılık ve hastalıklar toplumlar için sosyal ve ekonomik bir sorun haline gelmektedir. Türkiye'de yaşlılık üzerine yapılan çalışmalar giderek artmakta, farklı bakış açılarından birçok konu incelenerek tartışılmaktadır (Karahan, \& Güven, 2002).

\section{Yöntem}

Bu araştırma Ankara ilinde bulunan Gazi Üniversitesi Hastanesi, Atatürk Eğitim ve Araştırma Hastanesi, Ankara Ulus Hastanesi, Özel Yaşam, Özel Batıkent Yaşam Fizik Tedavi ve Rehabilitasyom Merkezleri'ne tedavi olmak için başvuran 65 yaş üstü 111 erkek, 101 kadın toplam 212 yaşlı hasta üzerinde yapılmıştır. Bu çalışmada veriler yaşlılarla yüz yüze görüşme tekniği uygulanarak toplanmıştır. Araştırmaya gönüllü olarak katılan yaşlılar, çalışma hakkında bilgilendirilerek sözlü onamları alınmıştır. Çalışma Helsinki Bildirgesi’ne uygun olarak yürütülmüştür. Anket formunda araştırma kapsamına alınan bireyler hakkında genel bilgiler, sağlık durumları, fiziksel aktivite durumları ve fizik tedavi ve rehabilitasyon merkezlerine başvurma nedenleri yer almıştır. Yaşlıların vücut ağırlıkları ve boy uzunlukları yöntemine uygun bir şekilde araştırmacılar tarafından ölçülerek kayıt edilmiş ve Beden Kitle İndeksi (BKİ) hesaplanmıştır. Veriler SPSS (Statistical Package for the Social Sciences V.12.0) programına aktarılmış $t$ ve ki kare testi kullanılarak sonuçlar istatistiksel olarak değerlendirilmiştir.

\section{Bulgular ve Tartışma}

Araştırma kapsamına alınan 111’i erkek 101’i kadın toplam 212 yaşlının demografik özellikleri Tablo 1'de verilmiştir. 
Tablo 1. Araştırmaya katılan bireylerin demografik özelliklerine göre dağı̆lımı.

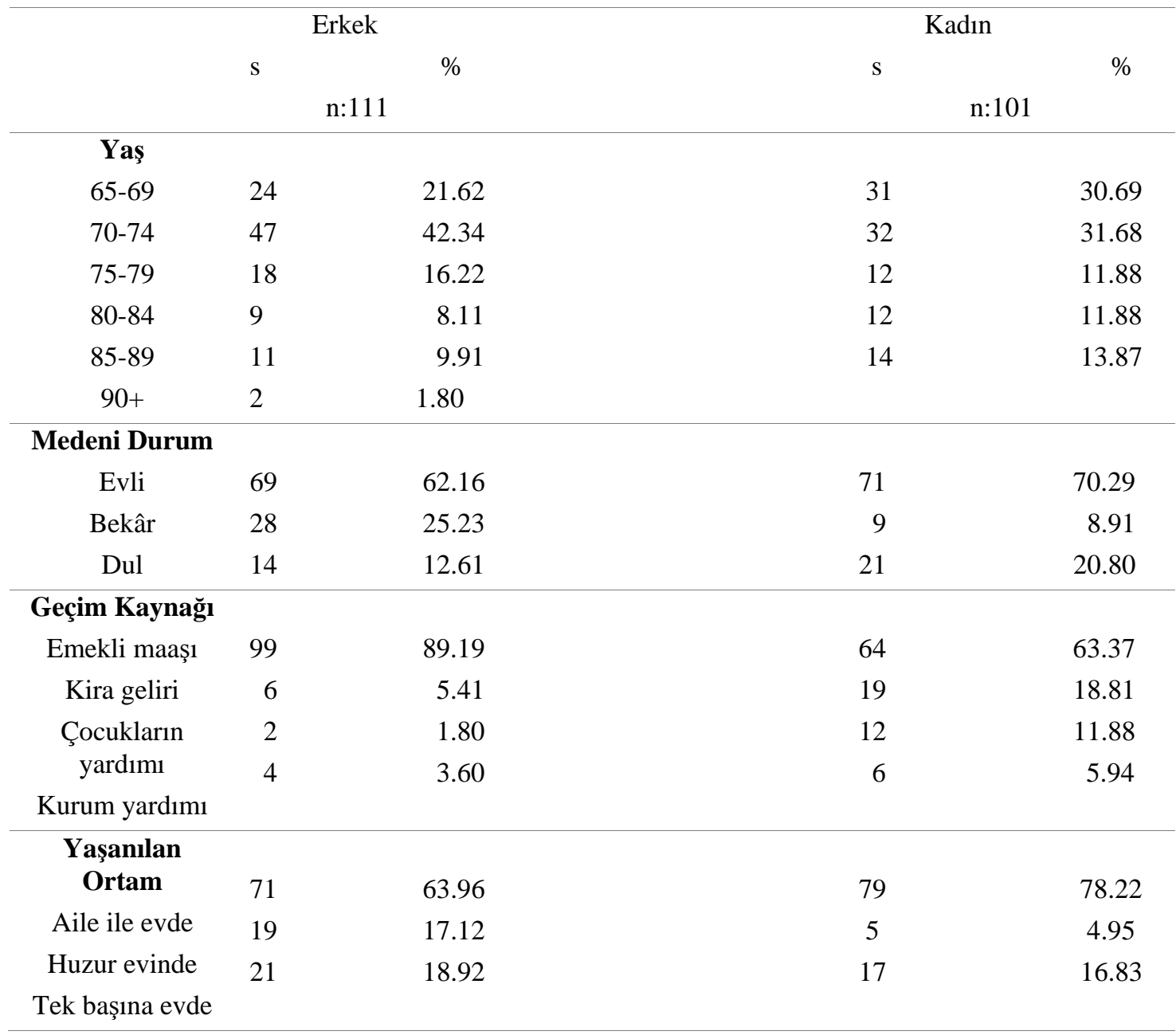

Tablo 1'de görüldüğü gibi araştırma kapsamına alınan yaşlıların \% 52.36'sı (111) erkek, \% 47.64'ü (101) kadındır. Erkeklerin \% 42.34'ü 70-74 yaşlarında \% 21.62'si ise 65-69 yaşları arasındadır. 90 yaş üstü \% 1.80 (2 kişi) bulunmaktadır. Kadınların ise \% 31.68'i 70-74 yaşları arasında \% 30.69'u ise 65-69 yaşları arasındadır. Erkeklerin \% 62.16'sı kadınların ise \% 70.29’u evlidir. Her iki grupta da erkeklerin \% 89.19’u, kadınların \% 63.37’si emekli maaşı ile geçimlerini sağlamaktadırlar.

Araştırma kapsamına alınan yaşlıların erkeklerde \%63.96’sı kadınlarda \%78.22'si aileleri ile birlikte \% 17.12'si huzurevinde \% 18.92'si ise evlerinde tek başlarına yaşamlarını sürdürmektedirler. Aynı şekilde kadınların da \% 78.22'si aileleri ile birlikte evde \% 4.95'i huzurevinde \% 16.83’ü ise evde tek başlarına yaşamlarını devam ettirmektedirler.

Yaşlıların büyük bir kısmının sosyal güvencesinin olması tedavi giderlerini ve ilaç kullanımını etkileyen önemli etkenlerden birisi olduğu aşikardır. Yaşlılık döneminin daha sağlıklı ve mutlu geçmesinde sağlık hizmetlerine ulaşımın kolaylaşmasının önemli bir rolü vardır.

Yaşlıların cinsiyetlerine göre yaş, vücut ağırlığı, boy uzunluğu ve BKİ’lerinin aritmetik ortalama $(\bar{x})$ ve standart hata (Sx) değerleri Tablo 2'de gösterilmiştir. 
Tablo 2. Yaşlıların cinsiyetlerine göre yaş, vücut ağırlığı, boy uzunluğu ve BKİ’erinin değerleri.

\begin{tabular}{lccccc}
\hline & \multicolumn{2}{c}{ Erkek (n=111) } & Kadın (n=101) & & \\
& $\overline{\mathbf{x}}$ & $\mathbf{S x}$ & $\overline{\mathbf{x}}$ & $\mathbf{S x}$ & $\boldsymbol{t}$ \\
\hline Yaş & 76.3 & 0.9 & 73.4 & 0.7 & $-2.8^{*}$ \\
Vücut Ağırlığı & 77.4 & 1.15 & 70.9 & 1.13 & 5.8 \\
Boy Uzunluğu & 176.6 & 1.18 & 161.9 & 0.8 & 8.9 \\
BKI $\left(\mathrm{kg} / \mathrm{m}^{2}\right)$ & 25.2 & 0.6 & 28.2 & 0.5 & $-0.87^{* *}$ \\
\hline${ }^{*} \mathrm{p}<0.01,{ }^{* *} \mathrm{p}<0.05$ & & & &
\end{tabular}

Tablo 2'de görüldüğg̈ gibi erkeklerde vücut ağırlığı, boy uzunluğu ve BKİ'leri sırasıyla $77.4 \pm 1.15,176.6 \pm 1.18$ ve $25.2 \pm 0.6 \mathrm{~kg} / \mathrm{m}^{2}$ ' dir. Kadınlarda ise vücut ağırlığı, boy uzunluğu ve BKİ'leri sırasıyla $70.9 \pm 1.13,161.9 \pm 0.8$ ve $28.2 \pm 0.5 \mathrm{~kg} / \mathrm{m}^{2}$ 'dir. Kadınların BKİ'leri erkeklere göre istatistiksel olarak anlamlı bir şekilde yüksek bulunmuştur $(p<0.05)$.

Yaşlanma ile birlikte bel/kalça oranında artma olduğu yapılan birçok çalışmada gösterilmiştir. Bunun sonucunda bel/kalça oranının ve bel çevresinin artmasıyla kan basıncı, açlık kan şekeri, serum total kolesterol düzeylerinin de yükseldiği saptanmıştır (Tytmonas, 2006; Gupta, et alii, 2007; Biggs, et alii, 2010; Lujain, Anwar, Yossif, \& Yossra, 2010). Yaşlanmanın yanı sıra menopoz sonrası kadınlar genelde kilo alma eğilimindedirler (Dubnov, Brzezinski, \& Berry, 2003).

Şahin et alii, 50-65 yaşlar arasındaki bireylerin antropometrik özelliklerini değerlendirmiş ve özellikle 60 yaş üstü bireylerde bel-kalça oranının arttığını saptamışlardır (Şahin, Toraman, \& Muratl, 2002).

Tablo 3. Yaşlıların cinsiyetlerine göre hastalıklarının dağılımı.*

\begin{tabular}{lcccc}
\hline Hastalık & \multicolumn{2}{c}{ Erkek (n=111) } & \multicolumn{2}{c}{ Kadın (n=101) } \\
& s & \% & s & \% \\
\hline Hipertansiyon & 83 & 74.77 & 71 & 70.3 \\
Romatizmal hastalıklar & 87 & 78.38 & 90 & 81.11 \\
Görme bozuklukları & 81 & 72.97 & 72 & 71.29 \\
Kalp damar hastalıkları & 91 & 81.98 & 82 & 81.18 \\
Reflü & 90 & 81.08 & 94 & 93.07 \\
Diyabet & 72 & 64.86 & 66 & 65.34 \\
Astım & 38 & 34.23 & 44 & 43.56 \\
Koah & 24 & 21.62 & 11 & 10.89 \\
Kırık (kalça, kol, bacak) & 55 & 49.55 & 68 & 67.33 \\
\hline
\end{tabular}

*Birden fazla seçenek işaretlenmiştir.

Tablo 3 incelendiğinde araştırma kapsamına alınan yaşlılarda en çok görülen hastalıkların başında her iki cinste de reflü, hipertansiyon, romatizmal hastalıklar (erkeklerde \% 78.38, kadınlarda \% 81.11), görme bozuklukları ve diyabet gelmektedir. Yaşlılardaki (kalça, el, bilek, ayak kemiği kırıkları) kadınlarda (\% 67.33) erkeklere (\% 49.55) göre daha fazla görülmektedir. Osteoporoz yaşlılarda önemli bir halk sorunu olarak kabul edilmektedir. Yaşlı kadınlarda osteoporoz sıklıkla görülmekle beraber yaşlı erkeklerde de küçümsenmeyecek oranlardadır. Osteoporozda bireyin boyu kısalır, şiddetli sırt ağrıları görülür ve el bileğinde, kalçada ve omurgada oluşabilecek kırıklar yaşlı bireyin yaşam kalitesini olumsuz yönde etkiler (Duque, \& Troen, 2008; Beaudreuil, 2006). Yaşlıların sağlık kontrolüne başvurma sıklıkları Tablo 4’te verilmiştir. Sağlık 
kontrolüne erkeklerin \% 12.61'i, kadınların \% 4.95'i doktor istediğinde, erkeklerin \% 14.41'i kadınların \% 14.85’i hastalandıklarında sağlık kuruluşuna başvurduklarını belirtmişlerdir. Tablo 4'deki sağlık kuruluşuna başvurma sıklıkları erkeklerde $n=91$, kadınlarda $n=81$ üzerinden değerlendirilmiştir.

Tablo 4. Yaşlıların sağlık kontrolüne başvurma sıklıkları.

\begin{tabular}{lllll}
\hline & \multicolumn{2}{c}{ Erkek (n=91) } & \multicolumn{2}{c}{ Kadın (n=81) } \\
\multicolumn{1}{c}{ Siklık } & s & \% & s & \% \\
\hline 2-3 günde bir & 7 & 7.70 & 16 & 19.75 \\
4-5 günde bir & 11 & 12.09 & 9 & 12.11 \\
Haftada bir & 16 & 17.57 & 13 & 16.05 \\
Ayda bir & 27 & 29.67 & 24 & 29.64 \\
3 ayda bir & 12 & 13.19 & 7 & 6.64 \\
6 ayda bir & 12 & 13.19 & 9 & 12.11 \\
Yllda bir & 6 & 6.59 & 3 & 3.70 \\
\hline
\end{tabular}

$\mathrm{X}^{2}: 87.61 \quad \mathrm{P}<0.05$ SD:6

Tablo 4’te de görüldüğü gibi yaşlı erkeklerin \% 29.67’si kadınların \% 29.64’ü ayda bir, sağlık kuruluşuna başvururken erkeklerin \% 7.70'i, kadınların \% 19.75’i doktor 2-3 günde bir sağlık kuruluşuna başvurmaktadır. Araştırmamızda kadınların erkeklere göre daha sık sağlık kuruluşlarına kontrol amaçlı gitmeleri istatistiksel açıdan anlamlı bulunmuştur. Yaşlıların pek çoğunda çeşitli sağlık sorunları görülmektedir. Bu nedenle yaşlıların sağlık sorunlarının saptanması için hastalıklara yönelik tarama çalışmalarının yapılması ayrı bir önem taşımaktadır. Böyle çalışmalarda yaşlıların evlerinde sağlık kontrolünden geçirilmeleri için yaşlı sağlığı hizmetlerinin birinci basamakta planlanması gerekmektedir (Turaman, 2001).

Tablo 5. Yaşlıların fiziksel aktivite durumları.

\begin{tabular}{llllll}
\hline Fiziksel Aktivite Türü & \multicolumn{2}{c}{ Erkek (n=111) } & \multicolumn{3}{c}{ Kadın (n=101) } \\
& s & \% & s & \% & \\
\hline Yürüyüş (tempolu) & & & & & \\
\hline Yapmıyor & 52 & 46.84 & 39 & 38.61 & $\mathrm{X}^{2}: 11.423$ \\
Ara sıra yapıyor & 47 & 42.34 & 58 & 57.43 & $\mathrm{P}<0.05$ \\
Devamlı yapıyor & 12 & 10.82 & 14 & 13.86 & SD:2 \\
\hline Kültür Fizik Hareketi & & & & & \\
\hline Yapmıyor & 48 & 43.24 & 80 & 79.21 & $\mathrm{X}^{2}: 13.611$ \\
Ara sıra yapıyor & 44 & 39.64 & 12 & 11.88 & $\mathrm{P}<0.05$ \\
Devamlı yapıyor & 18 & 16.22 & 9 & 8.91 & SD:2 \\
\hline Koşu & & & & & \\
\hline Yapmıyor & 51 & 45.94 & 48 & 47.52 & $\mathrm{X}^{2}: 4.662$ \\
Ara sıra yapıyor & 30 & 27.03 & 31 & 30.69 & $\mathrm{P}>0.05$ \\
Devamlı yapıyor & 30 & 27.03 & 29 & 28.71 & $\mathrm{SD}: 2$ \\
\hline
\end{tabular}

Aktivite yapma durumları incelendiğinde yaşlı erkek ve kadınların devamlı yürüyüş, egzersiz hareketi yapma ve koşu yapma durumları düşük bulunmuştur. Yapılan fiziksel aktivitelerden yürüyüş ve egzersiz hareketleri yapma durumları ile erkek ve kadınlar arasındaki fark istatistiksel açıdan önemli bulunurken $(\mathrm{p}<0.05)$ fiziksel aktivite olarak koşu yapan erkek ve kadınlar 
arasındaki fark istatistiksel açıdan önemli değildir. (p>0.05) Aktif yaşlanma insan yaşamı boyunca yaşam kalitesini yükseltmek için gereken fırsatların optimize edilme sürecidir. Düzenli, orta dereceli fiziksel aktivite yaşlılarda fonksiyonel düşüşü geciktirir. Aktif yaşam ve düzenli fiziksel aktivite mental sağlığı geliştirdiği gibi sosyal iletişimi de arttırır. Fiziksel faaliyetler, yaşlıların vücut fonksiyonlarının ve kapasitelerinin korunmasına yardımcı olmaktadır (Hautier, \& Bonnefoy, 2007; Taylor, 2013). Yaşlılarda yapılan araştırmalarda yaşlılarda ağrıyla birlikte hareketler en az düzeye inmekte, depresif karakter, uyku problemleri, yorgunluk ve yaşam kalitesinde düşme görülmektedir. Fizyoterapistler yaşlının mevcut duygu-algı ve motor fonksiyonlarındaki yetersizlikleri en aza indirmeyi hedefleyerek her yaşlıya uygun fizyoterapi ve rehabilitasyon programlarını planlayarak uygulamalar yapmalıdır (Kayıhan, 2009).

Tablo 6. Yaşlıların fizik tedavi ve rehabilitasyon merkezlerine başvurma nedenleri.

\begin{tabular}{|c|c|c|c|c|c|c|}
\hline \multirow[t]{2}{*}{ Başvurma nedenleri } & \multicolumn{2}{|c|}{$\begin{array}{l}\text { Erkek } \\
(\mathrm{n}=111)\end{array}$} & \multicolumn{2}{|c|}{ Kadın (n=101) } & \multirow[t]{2}{*}{$X^{2}$} & \multirow[t]{2}{*}{$\mathrm{P}$} \\
\hline & $\mathrm{S}$ & $\%$ & S & $\%$ & & \\
\hline Kırık sonrası tedavisi & 46 & 41.44 & 49 & 48.51 & 6.112 & $\mathrm{p}>0.05$ \\
\hline Romatizmal hastalıklar & 91 & 81.98 & 87 & 86.13 & 7.028 & $\mathrm{p}>0.05$ \\
\hline Felç (İnme) & 31 & 27.92 & 28 & 27.72 & 4.881 & $\mathrm{p}>0.05$ \\
\hline Boyun fitığ 1 & 25 & 22.52 & 32 & 31.68 & 1.963 & $\mathrm{p}<0.01$ \\
\hline Bel fittğı & 37 & 33.33 & 39 & 38.61 & 3.419 & $\mathrm{p}>0.05$ \\
\hline Nefes egzersizi & 30 & 37.03 & 19 & 18.81 & 2.509 & $\mathrm{p}<0.01$ \\
\hline
\end{tabular}

*Birden fazla seçenek işaretlenmiştir. SD:1

Tablo 6 incelendiğinde fizik-tedavi ve rehabilitasyon merkezlerine tedavi için başvuran yaşlıların merkeze gelme nedenleri sırasıyla erkek ve kadınlarda \%81.98, \%86.13'ü ( $\mathrm{p}>0.05$ ) romatizmal hastalıklar, \% 41.44, \% 48.51'i ( $>>0.05$ ) kırıklardan sonra tedavi amacıyla \% 27.92, \%27.72'si geçirilmiş ( $>0.05$ ) inme sonrası tedavi, \% 27.03, \% 18.81 astım, koah gibi hastalıklar nedeniyle $(\mathrm{p}<0.01)$ nefes egzersizleri için \% 22.52, \% $31.68(\mathrm{p}<0.01)$ boyun fittı̆ı tedavisi almak amacıyla merkezlere başvurdukları tespit edilmiştir.

Ülkemizde yaşlılar genellikle sedanter yaşam tarzını benimsemektedir. Yaşlılarda düzenli aktivite ve egzersiz alışkanlığı kazandırılması kısa ve uzun dönemde sağlıklı yaşlanmasının en önemli belirleyicisidir. Yaşlılarda fonksiyonların azalması, eklem hareketlerinin yavaşlaması, kas kuvveti, eklem mobilitesi ve kişinin koordinasyon problemleri ile yürüyüşlerindeki değişikliklere ve yaşıının düşmesine yol açmaktadır. Düşme yaşlılarda çok sık rastlanan bir durumdur. Yaşlı nüfusun \% 30’unu düşme korkusu etkilemektedir (Nakipoğlu, Tezen, \& Özgirgin, 2005; Atay, \& Akdeniz, 2011).

\section{Sonuç}

Yaşamın her dönemi farklılık göstermektedir. Yaşlılık da kendine özgü önemli birtakım özellikler barındırmaktadır. Yaşlılıkla birlikte ortaya çıkan pek çok belirtilerde bireysel farklılıklar görülse de bazı belirtiler genellikle yaşlılarda sıklıkla görülebilmektedir. Yaşlılıkla birlikte ortaya çıkan bazı yetersizlikler ve hastalıklar yaşlıların hareket alanlarını çeşitli düzeylerde sınırlandırmaktadır.

Yaşlıların aktif olmaları ve yaşamlarını sağlıklı ve kaliteli şekilde sürdürebilmeleri için düzenli aktivite programları düzenlenmelidir. Yaşlılığın her evresinde sağlığın korunması temel hedef olmalıdır. Yaşlanma ile birlikte sağlık problemleri artmakta ve yaşam kalitesi azalmaktadır. Çalışmamızda yaşlıların fizik tedavi ve rehabilitasyon merkezlerine daha çok romatizmal ağrı tedavileri için kırık ameliyatı sonrası tedavilerinde ve inme tedavileri için başvurdukları tespit edilmiştir. 
Sonuç olarak; nüfusun ülkemizde giderek yaşlanması ve yaşlılara götürülecek hizmetlerde disiplinlerarası yaklaşımlarla fizyoterapi ve rehabilitasyon programlarının etkin ve aktif politikalarının oluşturulması büyük önem taşımaktadır.

\section{KAYNAKÇA}

Atay, E., \& Akdeniz, M. (2011). “Yaşıllarda Düşme, Düşme Korkusu ve Bedensel Etkinlik”. GeroFam, 2 (1), 11-28.

Beaudreuil, J. (2006). “Traitements non Médicamenteux de l'ostéoporose”. Annales de Réadaptation et de Médecine Physique, 49 (8), 581-588.

Beğer, T., \& Yavuzer, H., (2012). "Yaşlılık ve Yaşlılık Epidemiyolojisi”. Klinik Gelişim, 25 (3), 1-3.

Biggs, M. L., Mukamal, K. J., Luchsinger, J. A., Ix J. H., Carnethon, M. R., Newman, A. B., de Boer IH, Strotmeyer, E. S., Mozaffarian, D., \& Siscovick, D. S. (2010). “Association between adiposity in midlife and older age and risk of diabetes in older adults". The Journal of the American Medical Association, 303 (24), 2504-2512.

Dubnov, G., Brzezinski, A., \& Berry, E. M. (2003). "Weight Control and the Management of Obesity After Menopause: the Role of Physical Activity”. Maturitas. Feb, 25, 44 (2), 89-101.

Duque, G., \& Troen, B. R. (2008). "Understanding the Mechanisms of Senile Osteoporosis: New Facts for a Major Geriatric Syndrome”. Journal of American Geriatric Society. May, 56 (5), 935-941.

Durmuş, D., Cantürk, F., \& Topal T. (2005). "Yaşlanma ile Kastaki Değişimler, Beslenme ve Egzersiz”. Türk Geriatri Dergisi, 8 (1), 37-43.

Eser F., Akbulut-Aktekin, L., Mermerci-Başkan, B., \& Bodur, H. (2008). "Yatarak Fizik Tedavi ve Rehabilitasyon Uygulanan 60 Yaş ve Üstü Osteoartroz Hastalarında Yaşam Doyumu ve Yaşam Kalitesinin Değerlendirilmesi”. Türk Geriatri Dergisi, 11 (4),169-173.

Gupta, R., Rastogi, P., Sarna, M., Gupta, V. P., Sharma, S. K., \& Kothari, K. (2007). "Body Mass Index, Waist Size Hip Ratio and Cardiovascular Risk Factors in Urban Subjects”. Journal of the Association of Physicians of India, 55, 621-627.

Hautier, C., \& Bonnefoy, M. (2007). “Training for Older Adults”. Annales de Réadaptation et de Médecine Physique, 50, 475-479.

Karahan, A., \& Güven, S. (2002). "Yaşlılıkta Evde Bakım”. Türk Geriatri Dergisi,5 (4), 155-159.

Kayıhan, H. (2009). “Geriatride Fizyoterapi ve Rehabilitasyon”. Akademik Geriatri Dergisi, 1, 82-89.

Lujain Anwar, A., Yossif, A. R., \& Yossra, K. H. (2010). "Sex Differences in the Impact of Body Mass Index (BMI) and Waist /Hip (W/H) Ratio on Patients with Metabolic Risk Factors in Baghdad". Global Journal of Health Science, 2 (2), 154-162.

Morrison, M. (1969). "Physiotherapy in Geriatric Rehabilitation”. Journal of Royal College of General Practitioners, 18 (84 Suppl 1), 33-35.

Nakipoğlu, F. G., Tezen, Ö., \& Özgirgin, N. (2005). "Fizik Tedavi Ve Rehabilitasyon Programına Aldığımız Geriatrik Hastaların Özellikleri ve Fonksiyonel Durumları”. Türk Geriatri Dergisi, 8 (2), 84-88.

Nalbant, S. (2006). "Yaşlanmanın Biyolojisi”. Türkiye Fiziksel Tıp ve Rehabilitasyon Dergisi, 52 (Özel Ek A), 12-17.

Ögüt, S., \& Atay, E. (2012). “Yaşlılık ve Oksidatif Stres”. Süleyman Demirel Üniversitesi Tıp Fakültesi Dergisi, 19 (2), 68-74.

Şahin, G., Toraman N. F., \& Muratll, S. (2002). “50-65 Yaş Arasındaki Bireylerin MaxVO2 ve Antropometrik Özelliklerinin Değerlendirilmesi”. Türk Geriatri Dergisi, 5 (2), 54-58.

Taylor, D. (2013). Physical Activity is Medicine for Older Adults. Postgraduate Medical Journal, 1-7. doi:10.1136/postgradmedj-2012-131366.

Turaman, C. (2001). "Yaşlı Sağlığı Hizmetlerinin Birinci Basamakta Planlanması”. Türk Geriatri Dergisi, 4 (1), 22-27. 
Tytmonas, G. (2006). “The Influence of Increased Body Mass Index and Abdominal Obesity on the Development of Metabolic Syndrome”. Medicine (Kaunas), 42 (2), 123-129.

World Populations Ageing. (2009). Kaynak:

http://www.un.org/esa/population/publications/WPA2009/WPA2009_WorkingPaper.pdf

World Health Organisation. (2011). Kaynak:

http://www.who.int/whosis/whostat/EN_WHS2011_Full.pdf

Sağlık Bakanlı̆̆ı Sağlık İstatistikleri Yıllığı 2010. (2011). Kaynak:

http://sbu.saglik.gov.tr/Ekutuphane/kitaplar/siy_2011.pdf 